\title{
Incidence of spinal disease and role of spinal radiotherapy in multiple myeloma
}

\author{
A.M. Sharma MD, ${ }^{* \dagger}$ M. Sackett, ${ }^{\dagger \ddagger}$ D. Bueddefeld MD, ${ }^{\S}$ P. Lambert, II A. Dubey MD, ${ }^{* \dagger}$ V. Wadhwa MD, ${ }^{\#}$
} R. Kotb $\mathrm{MD}^{+\neq}$and N. Ahmed $\mathrm{MD}^{*+}$

\begin{abstract}
Background Spinal disease (SPD) in multiple myeloma (Mм) can be a major source of morbidity in newly diagnosed patients and long-term survivors. We retrospectively assessed the incidence of spinal disease in patients newly diagnosed with myeloma, its effect on survival, and the possible effect of spinal radiation therapy (RT).
\end{abstract}

Methods Patients diagnosed with mm between 2010 and 2014 were identified through the provincial cancer registry. Plain radiography, computed tomography, and magnetic resonance imaging were reviewed to detect and document the type of SPD. Data related to RT and systemic therapy were collected. Kaplan-Meier and time-varying Cox regression models were used to describe overall survival.

Results Of 306 identified patients with newly diagnosed MM, 51\% had sPD, including $17 \%$ with lytic disease, $68 \%$ with compression fractures, and $15 \%$ with spinal cord compression. Of the patients with SPD, $61 \%$ received spinal RT. Of those patients, $84 \%$ received spinal RT within 3 months after their diagnosis. Median dose was 20 Gy. Most patients (89.2\%) received chemotherapy, and $22.5 \%$ underwent autologous stem-cell transplantation. Only 6 of the patients treated with spinal RT received re-irradiation to the same site. Overall survival was similar for patients with and without SPD. On multivariate analysis, spinal RT had no effect on survival.

Conclusions In patients newly diagnosed with MM, SPD is a common presentation. With current systemic therapy, the presence of SPD had no adverse effect on overall survival. The effect of spinal RT on overall survival was nonsignificant.

Key Words Multiple myeloma, spinal disease, radiotherapy

Curr Oncol. 2018 Dec;25(6):e539-e544

www.current-oncology.com

\section{BACKGROUND}

Multiple myeloma (MM) is a treatable, yet noncurable, malignancy that carries high morbidity, mainly because of associated spinal and extra-spinal bony disease. In recent years, newer systemic therapies have significantly improved the survival of patients with $\mathrm{MM}^{1-5}$. However spinal involvement remains a major source of morbidity at diagnosis and can greatly affect quality of life for myeloma survivors. Spinal radiotherapy (RT) is an important treatment modality in the management of $\mathrm{MM}$, being used in most patients with $\mathrm{MM}$ at some point during the course of their disease. Its primary use is for local control and palliation of symptoms ${ }^{6-8}$.

Here, we present a population-based retrospective analysis of patients diagnosed with Mм at a Canadian cancer centre, highlighting the incidence of spinal disease and the effect of spinal RT on outcomes in those patients, including need for re-irradiation and overall survival in the modern era of chemotherapy and diagnostic imaging.

\section{METHODS}

Before data extraction, research ethics approval was obtained from the University of Manitoba Research Ethics Board. Using the Manitoba Cancer Registry, all patients diagnosed with мм in Manitoba between 1 January 2010 and 31 December 2014 were identified. The date of diagnosis was set as the date of bone marrow aspirate or biopsy confirming the diagnosis of мM. Demographic, clinical, and treatment-related data, including age at diagnosis, 
sex, chemotherapy, radiation therapy, transplantation, and death information, were extracted from electronic and paper charts.

Using the provincial radiology Picture Archiving and Communication System, all patients diagnosed with spinal disease [lytic disease, vertebral compression fracture, spinal cord compression (Cc)] as reported on plain-film skeletal survey, computed tomography (CT) imaging, or magnetic resonance imaging (MRI) were identified. Vertebral compression fracture was defined as any significant loss of vertebral height identified by a radiologist on one of the imaging modalities. Spinal cc was defined as symptomatic anatomic compression of the cord resulting from osseous and or extraosseous disease seen on MRI. Radiotherapy data were extracted from the Eclipse radiation oncology system (Varian Medical Systems, Palo Alto, CA, U.S.A.). Data related to systemic therapy and autologous stem-cell transplantation were captured through the Varian Medical Systems medical oncology system. The end-of-study date was 31 December 2015.

Kaplan-Meier and time-varying Cox regression models were used to describe and predict overall survival. Treatment variables were included as time-varying predictors. Schoenfeld residual plots were used to test the proportional hazards assumption. Restricted cubic splines were used to test the assumption of linearity. Influence plots were used to detect influential outliers.

\section{RESULTS}

\section{Spinal Disease}

Based on bone marrow biopsy or aspirate, 306 patients with MM were identified. Of those patients, 291 (95\%) had plain-film skeletal surveys with or without CT or MRI; 190 (62\%) had spinal ст imaging; and 109 (36\%) had spinal MRI. Based on the radiology reports, 155 patients (50.7\%) were identified with spinal disease within 3 months of their diagnosis. Table I presents clinical and treatment characteristics of the patients stratified by the presence or absence of spinal disease.

\section{Spinal RT}

Of the 155 patients with spinal disease, $61 \%(n=95)$ received spinal RT. In the groups who did and did not receive spinal RT, 12 patients (12.6\%) and 15 patients (25\%) respectively had spinal lytic disease, $62(65.3 \%)$ and $43(71.7 \%)$ had spinal compression fractures, and $21(22.1 \%)$ and $2(3.3 \%)$ had spinal cc.

Of the 95 patients who received spinal RT, $84 \%(n=80)$ were treated within 3 months of their diagnosis. Table II compares the clinical and treatment characteristics of patients with spinal disease who did not receive spinal RT and who did receive RT either within 3 months or more than 3 months after their diagnosis. Of the patients who received spinal RT, $33(34.7 \%)$ received 30 Gy or more, and $43(45.3 \%)$ received $20 \mathrm{~Gy}$. The median radiation dose was 20 Gy. Table I shows the dose fractionation. Treatment with palliative RT at sites other than the spine was given to 36 patients with spinal disease (23\%) and to 30 patients without spinal disease (19.9\%), as described in Table I.
TABLE I Patient- and treatment-related data

\begin{tabular}{|c|c|c|}
\hline \multirow[t]{2}{*}{ Characteristic } & \multicolumn{2}{|c|}{ Spinal Disease } \\
\hline & No & Yes \\
\hline Patients (n) & 151 & 155 \\
\hline Mean age at Dx (years) & 70.47 & 68.07 \\
\hline \multicolumn{3}{|l|}{$\operatorname{Sex}[n(\%)]$} \\
\hline Women & $73(48.3)$ & $60(38.7)$ \\
\hline Men & $78(51.7)$ & $95(61.3)$ \\
\hline \multicolumn{3}{|l|}{ Chemotherapy [n (\%)] } \\
\hline Yes & $133(88.1)$ & $140(90.3)$ \\
\hline No & $18(11.95)$ & $15(9.7)$ \\
\hline \multicolumn{3}{|l|}{ Transplantation $[n(\%)]$} \\
\hline Yes & $34(22.5)$ & $35(22.6)$ \\
\hline No & $117(77.5)$ & $120(77.4)$ \\
\hline \multicolumn{3}{|l|}{ Radiotherapy ${ }^{\mathrm{a}}[n(\%)]$} \\
\hline Spinal & NA & $95(61)$ \\
\hline 8 Gy in 1 fraction & NA & $13(13.7)$ \\
\hline 20 Gy in 5 fractions & NA & $43(45.3)$ \\
\hline 30 Gy in $10-12$ fractions & NA & $27(28.4)$ \\
\hline $40-45$ Gy in $20-25$ fractions & NA & $6(6.3)$ \\
\hline Other dose and fractionation & NA & $6(6.3)$ \\
\hline Non-spinal & 30 (19.9) & $36(23)$ \\
\hline \multicolumn{3}{|l|}{ Follow-up (years) } \\
\hline Median & 2.13 & 1.74 \\
\hline Range & $1.06-3.15$ & $0.84-3.85$ \\
\hline
\end{tabular}

TABLE II Clinical and treatment characteristics of the patients with spinal disease by whether and when they received spinal radiotherapy (RT)

\begin{tabular}{|c|c|c|c|c|c|c|}
\hline \multirow[t]{2}{*}{ Variable } & \multicolumn{6}{|c|}{ Timing of spinal RT in relation to diagnosis } \\
\hline & \multicolumn{2}{|c|}{ None } & \multicolumn{2}{|c|}{$<3$ Months } & \multicolumn{2}{|c|}{$\geq 3$ Months } \\
\hline \multicolumn{7}{|l|}{ Age (years) } \\
\hline Mean & \multicolumn{2}{|c|}{$69.9 \pm 11.0$} & \multicolumn{2}{|c|}{$66.4 \pm 9.9$} & \multicolumn{2}{|c|}{$69.4 \pm 11.0$} \\
\hline \multicolumn{7}{|l|}{$\operatorname{Sex}[n(\%)]$} \\
\hline Women & 25 & (41.7) & 29 & (63.25) & 6 & (40.0) \\
\hline Men & 35 & (58.3) & 51 & (63.75) & 9 & (60.0) \\
\hline \multicolumn{7}{|c|}{ Non-spinal RT $[n(\%)]$} \\
\hline Yes & 0 & $(0.0)$ & 30 & (37.5) & 5 & (33.3) \\
\hline No & 60 & $(100.0)$ & 50 & $(62.5)$ & 10 & $(66.7)$ \\
\hline \multicolumn{7}{|c|}{ Transplantation [n (\%)] } \\
\hline Yes & 16 & $(26.7)$ & 17 & $(21.25)$ & 2 & (13.3) \\
\hline No & 44 & (73.3) & 63 & (78.75) & 13 & (86.7) \\
\hline \multicolumn{7}{|c|}{ Chemotherapy $[n(\%)]$} \\
\hline Yes & 51 & (85.0) & 73 & (91.25) & 15 & (100) \\
\hline No & 9 & $(15.0)$ & 7 & $(8.75)$ & 0 & $(0.0)$ \\
\hline
\end{tabular}




\section{Systemic Therapy}

Of the cohort overall, $89 \%$ (273 patients) received chemotherapy, and $22.5 \%$ (69 patients) underwent autologous stem-cell transplantation. Table i shows the proportion of patients with and without spinal disease who received chemotherapy and underwent transplantation. Of the patients with spinal disease, $85 \%(n=51)$ of those who did not receive spinal RT and $93 \%(n=88)$ of those who received spinal RT also received chemotherapy. Similarly, $27 \%(n=16)$ of those who did not receive spinal RT and $20 \%(n=19)$ of those who received spinal RT underwent stem-cell transplantation (Table II). The more commonly used chemotherapy regimens included dexamethasonebortezomib (34\%), cyclophosphamide-bortezomibdexamethasone $(15 \%)$, cyclophosphamide alternating with prednisone $(10 \%)$, bortezomib-cyclophosphamide alternating with prednisone $(10 \%)$, and bortezomibmelphalan-prednisone (10\%).

\section{Survival Analysis}

Median overall survival in the entire cohort was 2.67 years at a median follow-up of 1.93 years. In the entire cohort, 5 -year survival was $27.7 \%$. Overall survival was not significantly different in patients with and without spinal disease, with median survival being, respectively, 2.54 years and 3.59 years in those groups (hazard ratio: 1.102 ; $95 \%$ confidence interval: 0.81 to $1.50 ; p=0.536$; Figure 1). In univariable analysis, spinal and non-spinal RT was associated with a higher risk of death. However, the relationship between spinal $\mathrm{RT}$ and death became nonsignificant in the multivariable model, which included age at diagnosis, non-spinal RT, chemotherapy, and transplantation (Table III).

Further subset analysis revealed that, compared with patients who received spinal RT 3 months or more after their diagnosis, those who did not receive spinal RT or who received spinal RT within 3 months of their diagnosis had a lower risk of dying ( $p=0.004$; hazard ratio: $0.30 ; 95 \%$ confidence interval: 0.15 to 0.61 ; and hazard ratio: 0.44 ; $95 \%$ confidence interval: 0.22 to 0.87 ). However, that effect became nonsignificant in the multivariable model, which included age at diagnosis, non-spinal RT, chemotherapy, and transplantation (Table IV).

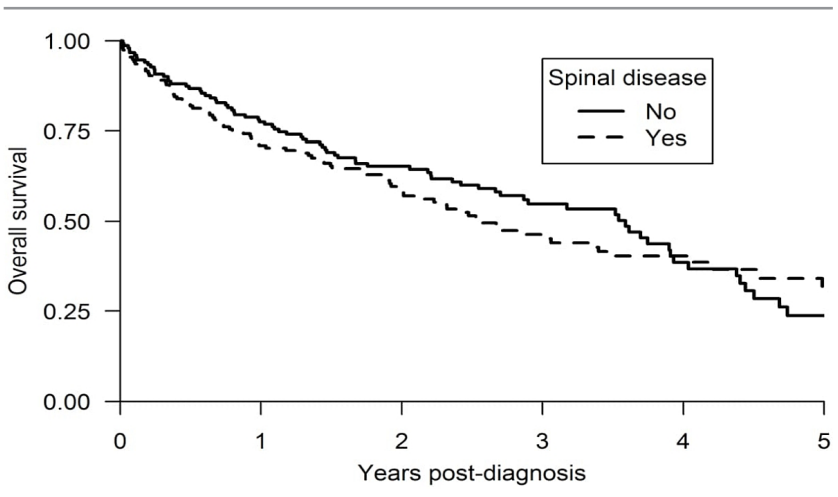

FIGURE 1 Kaplan-Meier survival curve for patients with and without spinal disease.

\section{Re-irradiation}

When analyzed for re-irradiation, only $7 \%$ of the patients who received spinal $\mathrm{RT}$ were re-irradiated at the same site within 5 years. However, $66 \%$ of the remaining patients died without re-irradiation to the same site within 5 years (Figure 2).

\section{DISCUSSION}

One of the most common manifestations of мм is osseous involvement, which is seen in up to $79 \%$ of patients at presentation and can affect any skeletal site. Osseous involvement ranges from lytic disease to compression fractures and spinal cc. Vertebral compression fractures can be seen in $22 \%$ of patients at presentation ${ }^{9}$. Pain and neurologic compromise are major causes of morbidity; the incidence of spinal cc has been documented to be $10 \%-24 \%$ in MM $^{10,11}$.

In addition to clinical presentation, imaging plays a crucial role in the diagnosis of spinal disease. Historically, a skeletal survey with plain radiography has been the most widely utilized imaging modality; however, its sensitivity for detecting lytic lesions is inferior to newer imaging modalities such as ст imaging, positron-emission tomography, and MRI. Magnetic resonance imaging is considered to be one of the most sensitive imaging modalities to detect boney lesions in мм. Imaging by ст is indicated when further clarification is needed to define the extent of soft-tissue involvement in relation to a bone lesion ${ }^{12,13}$. Positron-emission tomography is a valuable additional tool that is highly sensitive and specific for detecting bony lesions and extramedullary plasmacytomas ${ }^{14}$. Recently published guidelines from the European Society for Medical Oncology recommend low-dose whole-body ст as a new standard for the diagnosis of lytic disease in $\mathrm{MM}^{15}$.

In our study, most patients were initially screened using a skeletal survey; spinal CT and MRI were used in a limited number of the patients to confirm the presence of spinal disease. Because spinal disease was treated with RT in $61 \%$ of the patients with spinal involvement $(n=95)$, it is likely that most of the patients in our study underwent CT and or MRI because of symptomatic spinal disease rather than as a standard-of-care part of their initial evaluation. Furthermore, 9\% of our entire cohort had spinal lytic disease, and $34 \%$ had compression fractures. The incidence of vertebral compression fractures in our report is higher than the $22 \%$ previously documented by Kyle et al. ${ }^{9}$ in a large cohort of patients diagnosed between 1985 and 1998. In that particular study, only conventional radiography was used; our study showed the use of Ст and MRI in addition to plain radiography. For spinal cc, we used a strict definition, including findings on CT or MRI (or both) in addition to clinical presentation; $8 \%$ of the entire cohort presented with spinal CC, which is consistent with prior reports ${ }^{16}$.

Management of MM with spinal disease requires a multidisciplinary approach, with systemic therapy being the primary treatment, with or without spinal RT. Surgical intervention could be needed-initially to obtain a pathology diagnosis and to stabilize the spine, frequently followed by postoperative spinal $\mathrm{RT}^{17}$.

Interestingly, myeloma cells are uniquely radiosensitive. In vitro studies indicate low SF2 values (the fraction of 
SPINAL DISEASE IN MULTIPLE MYELOMA, Sharma et al.

TABLE III Patient- and treatment-related survival, Cox regression models

\begin{tabular}{|c|c|c|c|c|c|c|}
\hline \multirow[t]{2}{*}{ Variable } & \multicolumn{3}{|c|}{ Univariable model } & \multicolumn{3}{|c|}{ Multivariable model } \\
\hline & HR & $95 \% \mathrm{CI}$ & $p$ Value $^{\mathrm{a}}$ & HR & $95 \% \mathrm{Cl}$ & $p$ Value $^{\mathrm{a}}$ \\
\hline \multicolumn{7}{|l|}{ Spinal RT } \\
\hline >20 Gy & 1 & & & 1 & & \\
\hline 20 Gy & 1.73 & 0.96 to 3.13 & 0.026 & 1.75 & 0.94 to 3.23 & 0.100 \\
\hline$<20$ Gy & 1.66 & 0.77 to 3.55 & & 1.70 & 0.78 to 3.70 & \\
\hline None & 0.87 & 0.48 to 1.56 & & 1.00 & 0.51 to 1.97 & \\
\hline \multicolumn{7}{|l|}{ Non-spinal RT } \\
\hline Yes & 1.97 & 1.23 to 3.16 & 0.005 & 2.01 & 1.16 to 3.47 & 0.013 \\
\hline No & 1 & & & 1 & & \\
\hline \multicolumn{7}{|l|}{ Age at diagnosis } \\
\hline 10-Year increment & 1.71 & 1.38 to 2.11 & $<0.001$ & 1.60 & 1.23 to 2.07 & 0.001 \\
\hline \multicolumn{7}{|l|}{ Sex } \\
\hline Men & 0.94 & 0.62 to 1.42 & 0.760 & & & \\
\hline Women & 1 & & & & & \\
\hline \multicolumn{7}{|l|}{ Chemotherapy } \\
\hline$\geq 4$ Cycles & 0.17 & 0.07 to 0.40 & $<0.001$ & 0.20 & 0.08 to 0.49 & 0.002 \\
\hline 1-3 Cycles & 0.31 & 0.14 to 0.68 & & 0.36 & 0.16 to 0.80 & \\
\hline None & 1 & & & & 1 & \\
\hline \multicolumn{7}{|l|}{ Transplantation } \\
\hline Yes & 0.14 & 0.05 to 0.37 & $<0.001$ & 0.26 & 0.09 to 0.78 & 0.016 \\
\hline $\mathrm{No}$ & 1 & & & 1 & & \\
\hline
\end{tabular}

a Significant values shown in boldface type.

$\mathrm{HR}=$ hazard ratio; $\mathrm{Cl}=$ confidence interval; $\mathrm{RT}=$ radiotherapy.

TABLE IV Outcome of patients by the timing of receipt of spinal radiotherapy (RT), Cox regression models

\begin{tabular}{|c|c|c|c|c|c|c|}
\hline \multirow[t]{2}{*}{ Variable } & \multicolumn{3}{|c|}{ Univariable model } & \multicolumn{3}{|c|}{ Multivariable model } \\
\hline & HR & $95 \% \mathrm{Cl}$ & $p$ Value $^{\mathrm{a}}$ & HR & $95 \% \mathrm{Cl}$ & $p$ Value $^{\mathrm{a}}$ \\
\hline \multicolumn{7}{|l|}{ Spinal RT } \\
\hline$\geq 3$ Months post-Dx & 1 & & & 1 & & \\
\hline$<3$ Months post-Dx & 0.44 & 0.22 to 0.87 & 0.004 & 0.52 & 0.25 to 1.09 & 0.055 \\
\hline None & 0.30 & 0.15 to 0.61 & & 0.41 & 0.19 to 0.85 & \\
\hline \multicolumn{7}{|l|}{ Non-spinal RT } \\
\hline Yes & 1.97 & 1.23 to 3.16 & 0.005 & 2.17 & 1.22 to 3.84 & 0.008 \\
\hline No & 1 & & & 1 & & \\
\hline \multicolumn{7}{|l|}{ Age at Dx } \\
\hline 10-Year increment & 1.71 & 1.38 to 2.11 & $<0.001$ & 1.58 & 1.22 to 2.05 & 0.001 \\
\hline \multicolumn{7}{|l|}{ Sex } \\
\hline Men & 0.94 & 0.62 to 1.42 & 0.760 & & & \\
\hline Women & 1 & & & & & \\
\hline \multicolumn{7}{|l|}{ Chemotherapy } \\
\hline$\geq 4$ Cycles & 0.17 & 0.07 to 0.40 & $<0.001$ & 0.23 & 0.10 to 0.56 & 0.005 \\
\hline 1-3 Cycles & 0.31 & 0.14 to 0.68 & & 0.36 & 0.16 to 0.79 & \\
\hline None & 1 & & & 1 & & \\
\hline \multicolumn{7}{|l|}{ Transplantation } \\
\hline Yes & 0.14 & 0.05 to 0.37 & $<0.001$ & 0.26 & 0.09 to 0.77 & 0.015 \\
\hline No & 1 & & & 1 & & \\
\hline
\end{tabular}

a Significant values shown in boldface type.

$\mathrm{HR}=$ hazard ratio; $\mathrm{Cl}=$ confidence interval; $\mathrm{Dx}=$ diagnosis. 


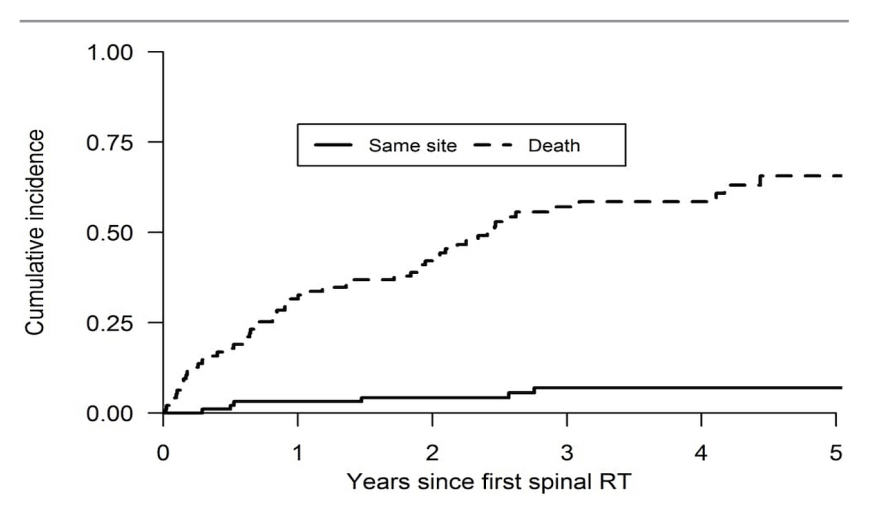

FIGURE 2 Incidence of same-site re-treatment and death in patients receiving spinal radiotherapy $(\mathrm{RT})$.

cells surviving at $2 \mathrm{~Gy}$ ), with an excellent clinical response to low-dose radiation ${ }^{18}$. The role of $\mathrm{RT}$ in MM is historical and has been recognized since $1931^{19}$. It can provide effective local control and can possibly cure solitary bone and extramedullary plasmacytomas ${ }^{20,21}$; however, the primary role of RT is palliative. While symptomatic patients are receiving systemic therapy, RT plays an important role in alleviating pain and offers local control of this debilitating disease. A large pool of published data indicates that most patients with MM require RT at some point during the course of their disease $\mathrm{e}^{6,7,22}$.

Talamo et al..$^{23}$ reviewed 449 patients with MM. In their study, patients were treated with RT to various sites, including spine. The median RT dose in the study was $30 \mathrm{~Gy}$ in 10 fractions. More than $70 \%$ of the 55 patients who were evaluated for pain control experienced a partial or complete response to RT. However, no significant effect on median overall survival was observed in a comparison with patients who received no RT (85 months vs. 108 months, $p=0.052$ ). Another retrospective review of 238 patients with MM and spinal cc treated with RT reported a response rate of $97 \%$, with $82 \%$ local control of the spinal disease after 3 years ${ }^{24}$.

In the present study, we specifically evaluated the outcomes of MM patients with and without spinal disease in the context of systemic therapy, stem-cell transplantation, and spinal RT. Median follow-up was 1.74 years and 2.13 years for patients with and without spinal disease respectively. Mean age of the patients at initial diagnosis and the proportions who received chemotherapy and transplantation were not significantly different in those groups. More men than women were affected by spinal disease. Patients with non-spinal disease also constituted a slightly higher proportion of the group with spinal disease. Interestingly, despite the greater disease burden in the spinal disease group, overall survival was similar for the patients with and without spinal disease. That observation is likely a result of the fact that patients in both groups were treated with chemotherapy and transplantation, which remain the primary treatments for MM.

Among the patients with spinal disease, the group that received spinal RT included a larger proportion of patients with spinal cc: 21 patients $(22.1 \%)$ compared with only 2 patients $(3 \%)$ in the group that did not receive spinal RT. However, the group treated with non-spinal RT included a larger proportion of patients with lytic disease and compression fractures. Interestingly, 60 of the patients who did not require spinal $\mathrm{RT}$ were also not treated with any non-spinal RT. In contrast, of the 95 patients who required spinal RT, 37\% $(n=35)$ also required non-spinal RT. We believe that a significant proportion of the patients with spinal CC and disease burden other than spine requiring non-spinal RT might have contributed to the higher risk of death in the spinal RT group. But that assumption cannot be verified without knowing the performance status of those patients and their clinical and radiologic response to RT. However, that difference in risk of death became nonsignificant when the age of the patients and chemotherapy and transplantation were taken into account. Hence, for several reasons, we have not been able to demonstrate with certainty either any beneficial or adverse effect of spinal RT on survival or local control. First, spinal RT in our cohort was given entirely for palliative purposes, with a wide range of doses and fractionation. Second, although only a small number of patients $(7 \%)$ required re-irradiation, the fact that about two thirds of the patients died during a period of 5 years made it difficult to determine the need for irradiation to the same site. In 6 patients who required re-irradiation, chemotherapy was also given. Finally, most patients in the spinal disease cohort were managed with chemotherapy and transplantation regardless of their need for spinal RT.

Generally, 30 Gy in 10-15 fractions achieves excellent symptomatic control in patients with $\mathrm{MM}^{25}$. However, whether in context of modern systemic therapy the RT dose fractionation scheme and survival are correlated is unknown. In our cohort of patients, it is interesting to note that risk of death was lower in patients who received more than 20 Gy to the spine than in patients who received 20 Gy or less. However, given the small number of patients in each dose range, the power for that comparison would have been limited.

\section{Limitations of the Study}

This was a retrospective study. Patient selection for spinal RT, absence of a well-defined RT dose fractionation protocol, and absence of documentation for toxicity, quality of life, performance status, and imaging after the spinal RT to demonstrate objective treatment response all pose difficulties in determining the effect of spinal RT on local control and overall survival.

\section{CONCLUSIONS}

This large institutional review complements the existing literature concerning the incidence of spinal disease in patients with newly diagnosed MM. It remains unclear whether, in the context of modern chemotherapy and stem-cell transplantation, spinal RT is related to overall survival in patients with MM. Considering the impressive radiosensitivity of myeloma cells, the spinal disease burden at presentation, and the routine clinical use of spinal RT in this population, a multicentre prospective study with a well-defined spinal RT protocol is needed. Modern RT techniques, including intensity-modulated RT and imageguided RT can be used to deliver a hypofractionated 
regimen with perhaps a higher RT dose. Currently, patients with Mм are excluded from stereotactic body RT protocols ${ }^{26}$. However, the principles of stereotactic body RT might be able to be exploited to deliver a dose of RT that provides effective local control with the least toxicity and that possibly triggers the abscopal effect, with its potential to affect overall survival-a novel concept to explore ${ }^{27,28}$.

\section{ACKNOWLEDGMENTS}

This work was presented as a poster at the 59th Annual Meeting of the American Society of Therapeutic Radiation Oncology; San Diego, CA, U.S.A.; 24-27 September2017; and the 2017 Annual Scientific Meeting of Canadian Association of Radiation Oncology; Toronto, ON; 13-16 September 2017.

\section{CONFLICT OF INTEREST DISCLOSURES}

We have read and understood Current Oncology's policy on disclosing conflicts of interest, and we declare that we have none.

\section{AUTHOR AFFILIATIONS}

*Department of Radiation Oncology, CancerCare Manitoba, ${ }^{\dagger} \mathrm{Max}$ Rady College of Medicine, University of Manitoba, ${ }^{\ddagger}$ Department of Hematology and Oncology, CancerCare Manitoba, §Department of Radiology, Max Rady College of Medicine, University of Manitoba, and IDepartment of Epidemiology, CancerCare Manitoba, Winnipeg, MB; ${ }^{\#}$ Department of Radiology, New York-Presbyterian Hospital, New York, NY, U.S.A.

\section{REFERENCES}

1. United States, Department of Health and Human Services, National Institutes of Health, National Cancer Institute (NCI), Cancer Stat Facts: Myeloma [Web page]. Bethesda, MD: NCI; 2018. [Available at: https://seer.cancer.gov/statfacts/html/ mulmy.html; cited 25 October 2018]

2. Palumbo A, Avet-Loiseau H, Oliva S, et al. Revised International Staging System for multiple myeloma: a report from International Myeloma Working Group. J Clin Oncol 2015;33:2863-9.

3. Kumar SK, Rajkumar SV, Dispenzieri A, et al. Improved survival in multiple myeloma and the impact of novel therapies. Blood 2008;111:2516-20.

4. Brenner H, Gondos A, Pulte D. Recent major improvement in long-term survival of younger patients with multiple myeloma. Blood 2008;111:2521-6.

5. Palumbo A, Cavallo F, Gay F, et al. Autologous transplantation and maintenance therapy in multiple myeloma. NEnglJMed 2014;371:895-905.

6. Mill WB, Griffith R. The role of radiation therapy in the management of plasma cell tumors. Cancer 1980;45:647-52.

7. Bosch A, Frias Z. Radiotherapy in the treatment of multiple myeloma. Int J Radiat Oncol Biol Phys 1988;15:1363-9.

8. Lee JW, Lee JE. Local radiotherapy for palliation in multiple myeloma patients with symptomatic bone lesions. Radiat Oncol J 2016;34:59-63.

9. Kyle RA, Gertz MA, Witzig TE, et al. Review of 1027 patients with newly diagnosed multiple myeloma. Mayo Clin Proc 2003;78:21-33.

10. Wallington M, Mendis S, Premawardhana U, Sanders P, Shahsavar-Haghighi K. Local control and survival in spinal cord compression from lymphoma and myeloma. Radiother Oncol 1997;42:43-7.

11. Woo E, Yu YL, Ng M, Huang CY, Todd D. Spinal cord compression in multiple myeloma: who gets it? Aust NZJMed 1986;16:671-5.

12. Hanrahan CJ, Christensen CR, Crim JR. Current concepts in the evaluation of multiple myeloma with Mr imaging and FDG PET/CT 1. Radiographics 2010;30:127-42.

13. Dimopoulos M, Terpos E, Comenzo RL, et al. International Myeloma Working Group consensus statement and guidelines regarding the current role of imaging techniques in the diagnosis and monitoring of multiple myeloma. Leukemia 2009;23:1545-56.

14. Cavo M, Terpos E, Nanni C, et al. Role of ${ }^{18}$ F-FDG PET/CT in the diagnosis and management of multiple myeloma and other plasma cell disorders: a consensus statement by the International Myeloma Working Group. Lancet Oncol 2017;18:e206-17.

15. Moreau P, San Miguel J, Sonneveld P, et al. on behalf of the EsMo Guidelines Committee. Multiple myeloma: ESMO clinical practice guidelines for diagnosis, treatment and follow-up. Ann Oncol 2017;28(suppl 4):iv52-61.

16. Rades D, Abrahm JL. The role of radiotherapy for metastatic epidural spinal cord compression. Nat Rev Clin Oncol 2010;7:590-8.

17. Zadnik PL, Goodwin CR, Karami KJ, et al. Outcomes following surgical intervention for impending and gross instability caused by multiple myeloma in the spinal column. J Neurosurg Spine 2015;22:301-9.

18. Deacon J, Peckham MJ, Steel GG. The radioresponsiveness of human tumours and the initial slope of the cell survival curve. Radiother Onco 1984;2:317-23.

19. Coley WB. Multiple myeloma. Ann Surg 1931;93:77-89.

20. Reed V, Shah J, Medeiros LJ, et al. Solitary plasmacytomas: outcome and prognostic factors after definitive radiation therapy. Cancer 2011;117:4468-74.

21. Krause S, Hillengass J, Goldschmidt H, Debus J, Neuhof D. Radiotherapy of solitary plasmacytoma. Ann Hematol 2011;90:1093-7.

22. Leigh BR, Kurtts TA, Mack CF, Matzner MB, Shimm DS. Radiation therapy for the palliation of multiple myeloma. Int $J$ Radiat Oncol Biol Phys 1993;25:801-4.

23. Talamo G, Dimaio C, Abbi KK, et al. Current role of radiation therapy for multiple myeloma. Front Oncol 2015;5:40.

24. Rades D, Conde-Moreno AJ, Cacicedo J, Segedin B, Rudat V, Schild SE. Excellent outcomes after radiotherapy alone for malignant spinal cord compression from myeloma. Radiol Oncol 2016;50:337-40.

25. Adamietz IA, Schober C, Schulte RW, Peest D, Renner K. Palliative radiotherapy in plasma cell myeloma. Radiother Oncol 1991;20:111-16.

26. Greco C, Pares O, Pimentel N, et al. Spinal metastases: from conventional fractionated radiotherapy to single-dose sBRT. Rep Pract Oncol Radiother 2015;20:454-63.

27. Saba R, Saleem N, Peace D. Long-term survival consequent on the abscopal effect in a patient with multiple myeloma. BMJ Case Rep 2016;2016:pii:bcr2016215237.

28. Siva S, MacManus MP, Martin RF, Martin OA. Abscopal effects of radiation therapy: a clinical review for the radiobiologist. Cancer Lett 2015;356:82-90. 